This is a pre-copyedited, author-produced version of an article accepted for publication in The British Journal of Social Work following peer review. The version of record Hood, Rick, Goldacre, Allie, Gorin, Sarah and Bywaters, Paul (2020) Screen, ration and churn : demand management and the crisis in children's social care. The British Journal of Social Work, 50(3), pp. 868-889. is available online at: https://doi.org/10.1093/bjsw/bcz035

\title{
Screen, ration and churn: demand management and the crisis in children's social care
}

\section{Abstract}

This paper presents findings from a quantitative study of the national datasets for statutory children's social care services in England. The aim of the study was to examine how demand management varied in local authorities with differing levels of area deprivation. 152 LA census returns and other statistical indicators covering the period 2014-17 were combined into a single dataset. Statistical analysis was undertaken to explore trends over time and correlations between indicators that might indicate patterns in the way demand was managed. Findings showed that that high levels of deprivation have continued to be strongly linked to high levels of activity and that local authorities have continued to increase their use of protective interventions relative to referrals. Evidence was found for three interconnected mechanisms, through which local authorities tended to manage demand for services: screening, rationing and workforce churn. The paper describes these mechanisms and comments on their significance for the current crisis of demand in the sector.

Keywords: children's social care, child protection, demand, intervention, management, quantitative analysis 
Hood, R., Goldacre, A., Gorin, S. and Bywaters, P. (2019) Screen, ration and churn: demand management and the crisis in children's social care, British Journal of Social Work (in press)

\section{Introduction}

Children's social care (CSC) comprises a range of services including children's centres, early intervention and family support, services to protect children from abuse and neglect, as well as services for children in public care (looked after children). CSC services in England are mainly provided by local authorities (LAs), although a more mixed picture of provision has begun to emerge in recent years. This paper is mainly concerned with the safeguarding remit of CSC, i.e. assessments and interventions following referral to statutory services up to the point of a court order or other provision for permanent care of a child. This covers activity such as child and family assessments, children in need (CIN) plans, child protection (CP) investigations, CP case conferences, (CP) plans, and care proceedings. Services for looked after children overlap with safeguarding, particularly when these arrangements are short-term or temporary, but also constitute a distinct tier of provision for the minority of children who cannot remain with their birth families.

At the time of writing, CSC services in England are widely reported to be in (or near) crisis, due to a combination of rising demand and large cuts to central government funding (ADCS, 2017; LGA, 2017; Thomas, 2018). These pressures have disproportionately affected more deprived LAs, where child poverty has risen faster and changes to funding formulas have reduced the resources available to LAs (Webb and Bywaters, 2018). The cuts have not been evenly distributed; spending on early intervention (e.g. family support) has been slashed since 2011, while funding for late intervention (e.g. CP investigations) has actually increased (Action for Children et al., 2017). Before considering these trends further, it is worth emphasising the sheer scale of referrals to CSC services, which according to a recent study now have contact with more than one in five children before their fifth birthday (Bilson and Martin, 2016). As Devine and Parker (2015) point out, such figures represent a huge increase from the levels recorded in 1992, when comparable data started to be collected. Nonetheless, the most significant trend in recent years has not been an increase in referrals but rather the acceleration in CP and court work (Hood et al., 2016a; Bilson et al., 2017). Allied to an already-high level of referrals, demand for 'late intervention' is placing unsustainable pressure on LA budgets.

These trends largely affect children and families living in poverty, the main recipients of child welfare services. Most cases of child abuse involve the assessment of neglect and emotional abuse (DfE, 2017), which are cumulative in their developmental impact and tend to intersect with the adverse consequences of poverty and social exclusion (Thoburn et al., 2000). Recent research has shown that 
Hood, R., Goldacre, A., Gorin, S. and Bywaters, P. (2019) Screen, ration and churn: demand management and the crisis in children's social care, British Journal of Social Work (in press)

neighbourhood deprivation significantly affects a child's chances of being subject to a CP intervention (Bywaters et al., 2018). The connection with structural disadvantage is perhaps the most worrying aspect of the rebalancing of services towards $\mathrm{CP}$ at the expense of preventative work, along with the wider social impact on families and communities (Broadhurst and Mason, 2017). When it comes to protective services, levels of demand - in the sense of claims on an agency's resources - are more than just a reflection of deprivation-related risk factors or need in the community. The regulatory functions of CSC, through which agencies help to enforce socially acceptable standards of parental care and other aspects of family life, are sensitive to the attitudes and perceptions of many stakeholders, including service users, practitioners, managers, politicians, the media, and the general public. There are many ways in which demand can be managed, and the interests and priorities of stakeholders may not necessarily be aligned. It is therefore important to explore demand management both as a concept and as an empirical phenomenon in CSC.

\section{Demand management in children's social care}

Demand for CSC starts off as a referral, often from other services in the community, and is assessed at various points to determine eligibility for different types of provision. Families may be reluctant to share their problems with child welfare agencies and indeed may disagree with the 'need' for a service as defined by referrers at the initial point of contact or subsequently in professional assessments and reports. Nonetheless, referrals are managed on the basis of assessment via a series of 'filters and funnels' (Gibbons et al., 1995; Hood et al., 2016a). These are internal thresholds designed to screen out or retain cases at different levels of need and risk. Although services are configured differently in different LAs, certain common thresholds are suggested by the legislative underpinning of CSC, as described below. LAs collect administrative data on cases that meet (and do not meet) these thresholds and report them to the Department for Education (DfE) on an annual basis. Statistics on care proceedings are collected and reported by the Children and Family Court Advisory and Support Service (CAFCASS). The main exception is data on pre-proceedings work, which at the time of writing is neither routinely collected nor publicly reported except in research (Masson and Dickens, 2013). The main thresholds following referral to CSC are summarised below in Table 1 :

Table 1. Thresholds following referral to CSC 
Hood, R., Goldacre, A., Gorin, S. and Bywaters, P. (2019) Screen, ration and churn: demand management and the crisis in children's social care, British Journal of Social Work (in press)

\begin{tabular}{|l|l|}
\hline Threshold & Comments \\
(NFA) Further Action & $\begin{array}{l}\text { Following initial screening the referral is closed without further } \\
\text { assessment. }\end{array}$ \\
\hline Statutory & $\begin{array}{l}\text { A child and family assessment is undertaken on the new referral. Prior to } \\
\text { 2013, this would have been called an 'initial assessment'. }\end{array}$ \\
\hline Assessed Not CIN & $\begin{array}{l}\text { Following assessment, the child is found not to be 'in need'. Such cases } \\
\text { may be referred to a non-statutory service or 'early help' provision }\end{array}$ \\
\hline $\begin{array}{l}\text { Children in Need } \\
\text { (CIN) }\end{array}$ & $\begin{array}{l}\text { Following assessment, the child is found to be 'in need' as defined in } \\
\text { Section 17 of the 1989 Children Act (CA1989). CIN often have complex } \\
\text { needs and are entitled to receive a statutory service, usually a multi- } \\
\text { agency plan coordinated by a social worker. CIN plans are reviewed } \\
\text { regularly in a multi-agency meeting involving the family, whose consent is } \\
\text { required. }\end{array}$ \\
\hline Child Protection (CP) & $\begin{array}{l}\text { Section 47 of the CA1989 sets out the local authority's duty to investigate, } \\
\text { which includes cases where they have 'reasonable cause to suspect that a } \\
\text { child who lives, or is found, in their area is suffering, or is likely to suffer, } \\
\text { significant harm'. This duty overrides consent (although statutory } \\
\text { guidance emphasises that agencies should seek to work in partnership } \\
\text { with families). CP interventions encompass strategy meetings, Section 47 } \\
\text { investigations, CP case conferences and CP plans. CP plans are reviewed in } \\
\text { multi-agency ('core group') meetings as well as in CP conferences. }\end{array}$ \\
\hline $\begin{array}{l}\text { Public law outline } \\
\text { (PLO) }\end{array}$ & $\begin{array}{l}\text { Statutory guidance (DfE, 2014) sets out the duties of local authorities who } \\
\text { are considering applying to court to ask for a Care Order or Supervision } \\
\text { Order in respect of a child. This is sometimes described as 'initiating care } \\
\text { proceedings'. Care proceedings should take no longer than 26 weeks, } \\
\text { although the PLO also encompasses pre-proceedings work with the family. } \\
\text { A court will only make a Care or Supervision Order if it is satisfied that the } \\
\text { threshold criteria in Section 31 of the CA1989 have been met, so the local } \\
\text { authority will have regard to these criteria when deciding whether or not } \\
\text { to initiate care proceedings }\end{array}$ \\
\hline
\end{tabular}

These thresholds serve a dual purpose. First they ensure that CSC services comply with the legislation and statutory guidance. For example, the distinction between services provided under Sections 17 and 47 of the 1989 Children Act serves as a legal marker of the shift from consent to coercion, prevention to protection, family support to parental policing. Decisions relating to this threshold tend to be made by professionals and managers, while the threshold criteria in Section 31 require legal advice and ultimately a court order. Underpinning these thresholds is a set of legal checks and balances, which seek to ensure that children are supported by the state and protected from abuse while guarding against draconian and disproportionate interference in private family life. In this way, thresholds can be seen as an effort to manage what Devine (2015) has called the 'welfare-policing' dichotomy in CSC.

The same thresholds also serve a second purpose, which is to manage demand. A reference point here is the tiered system of public health, which is divided into universal/primary, 
Hood, R., Goldacre, A., Gorin, S. and Bywaters, P. (2019) Screen, ration and churn: demand management and the crisis in children's social care, British Journal of Social Work (in press)

specialist/secondary and acute/tertiary care (Hood, 2015). The dichotomy of care and control is replaced by a vertical continuum of need and risk. Each successive tier corresponds to a different level of need, so that more complex and acute cases are referred 'up' to appropriate specialists in the higher tiers, targeting expertise and resources at those children who most need it (Hardiker et al., 1991). Since higher tier services are more expensive, managing demand is also a way of managing cost. CSC can be considered a specialist tier of provision within children's services as a whole, since it usually requires a referral from another agency, but also operates its own internal tiers, which correspond to the thresholds listed above. Once a referral is accepted, a child is moved between different teams and social workers depending on how their level of need and risk is assessed and acted on. 'Eligibility' for CP and other types of higher tier provision, e.g. family recovery projects, requires the child to be judged at risk of harm. When this risk is no longer present, the child is 'stepped down' to less intensive (and intrusive) services with a view to closing their involvement with CSC. Intervention pathways therefore range from very brief (a referral receives no further action) to very lengthy (multiple assessments, care plans, escalations, and step-downs across different thresholds over several months or even years).

In a filter-and-funnel system, demand management may or may not correspond to the intentions of the legislation. For example, in their study of administrative data on CSC, Hood et al. (2016a) found evidence that patterns of service provision varied in LAs according to their level of demand. LAs (LAs) with higher levels of deprivation experienced higher levels of demand at every threshold described above. High-deprivation-high-demand LAs tended to screen out more referrals, divert more cases to non-statutory services, step down CIN and CP plans more quickly, were less likely to work longer term with families, and had higher rates of re-referrals within 12 months, compared to lowdeprivation-low-demand LAs. These patterns were connected with expenditure and workforce indicators. Spending on children's safety per LA child population was found to be higher in more deprived areas, while LAs with high levels of spending tended to have higher numbers of CIN per social worker and higher rates of agency workers. The findings suggested that these were characteristic ways of managing demand. However, since the study's design was exploratory and some of the indicators had only been reported for two years, further empirical work was undertaken as described below.

\section{Methods}

This study posed the following research questions: 
Hood, R., Goldacre, A., Gorin, S. and Bywaters, P. (2019) Screen, ration and churn: demand management and the crisis in children's social care, British Journal of Social Work (in press)

1. What were the changes in demand for, and provision of, CSC services from 2014-2017, compared with the previous five years?

2. How did patterns of service provision vary in relation to deprivation-related demand, expenditure and workforce indicators?

3. What does the analysis of trends and correlations tell us about how CSC services manage demand?

The research questions were addressed through a study of national data returns for English LAs, largely replicating the methods described in Hood et al. (2016a). These statistics are collected annually by the Department for Education and Cafcass (for care proceedings) and published in aggregated form for each LA. For this study, indicators relating to demand and provision were sourced from the CIN Census, and are listed below in Table 2 (with reference to the thresholds in Table 1). Indicators relating to deprivation levels, expenditure and workforce were taken from other sources as listed in Table 3. All years of expenditure were adjusted for inflation using the 2016-17 GDP deflator index published by the government (HM Treasury, 2017). For a more comprehensive overview of these statistical returns see Hood et al. (2016a: 928).

Table 2. Indicators of demand and provision at different thresholds

\begin{tabular}{|l|l|l|}
\hline Threshold & Indicator (Source: CIN Census) & Years available \\
\hline \multirow{3}{*}{ R. Referral } & Number of referrals & $2009-17$ \\
\cline { 2 - 3 } & Referrals within 12 months of a prior referral & $2009-17$ \\
\hline 1. No further action & Referrals not assessed & $2011-17$ \\
\hline $\begin{array}{l}\text { 2. Assessment carried } \\
\text { out }\end{array}$ & Continuous Assessments & $2013-17$ \\
\hline 3. Assessed but not CIN & Referrals assessed but deemed not CIN & $2011-17$ \\
\hline $4 . \quad$ Child in Need (CIN) & $\begin{array}{l}\text { Number of children starting an episode of } \\
\text { need }\end{array}$ & $2009-17$ \\
\cline { 2 - 3 } & $\begin{array}{l}\text { Number of Children in Need (CIN) at March } \\
31^{\text {st }}\end{array}$ & $2009-17$ \\
\cline { 2 - 3 } & Number of CIN during the year \\
\cline { 2 - 3 } & Number of CIN ending an episode of need & $2009-17$ \\
\cline { 2 - 3 } & $\begin{array}{l}\text { CIN Cease times (<3 months, 3-5 months, 6-11 } \\
\text { months, 1-2 years, 2+ years) }\end{array}$ & $2009-17$ \\
\hline \multirow{5}{*}{$5 . \quad$ Child Protection } & Numbers of Section 47 investigations & $2009-17$ \\
\hline & Number of CP conferences & $2009-17$ \\
\hline & Number of CP plans at March 31st & $2009-17$ \\
\cline { 2 - 3 } & $\begin{array}{l}\text { Number of CP plans that started during the } \\
\text { year }\end{array}$ & $2009-17$ \\
\cline { 2 - 3 } & Number of CP plans ceased & $2009-17$ \\
\hline
\end{tabular}


Hood, R., Goldacre, A., Gorin, S. and Bywaters, P. (2019) Screen, ration and churn: demand management and the crisis in children's social care, British Journal of Social Work (in press)

\begin{tabular}{|l|l|l|}
\hline \multirow{2}{*}{} & $\begin{array}{l}\text { CP plan cease times (<3 months, 3-5 months, } \\
\text { 6-11 months, 1-2 years, 2+ years) }\end{array}$ & $2009-17$ \\
\cline { 2 - 3 } & CP plans where children had a prior CP plan & $2009-17$ \\
\hline \multirow{3}{*}{$\begin{array}{l}\text { 6. Public Law Outline } \\
\text { (PLO) }\end{array}$} & Number of care proceedings during year & $2009-17$ \\
\cline { 2 - 3 } & $\begin{array}{l}\text { Number of care orders that started during } \\
\text { year }\end{array}$ & $2009-17$ \\
\cline { 2 - 3 } & $\begin{array}{l}\text { Number of Looked After Children on care } \\
\text { orders }\end{array}$ & $2009-17$ \\
\hline
\end{tabular}

Table 3. Other indicators

\begin{tabular}{|l|l|l|l|}
\hline Type & Indicator & Source & Years available \\
\hline Deprivation & $\begin{array}{l}\text { Index of Multiple } \\
\text { Deprivation (IMD) }\end{array}$ & $\begin{array}{l}\text { Office for National Statistics } \\
(2015)\end{array}$ & 2015 \\
\hline Expenditure & Total Spend on children & \\
\cline { 2 - 4 } & $\begin{array}{l}\text { Spend on children's } \\
\text { safety }\end{array}$ & Section 251 outturn & $2013-17$ \\
\hline \multirow{5}{*}{ Workforce } & CIN per social worker & $\begin{array}{l}\text { Children's Social Care Workforce } \\
\text { data collection (CSCW) }\end{array}$ & $2013-17$ \\
\cline { 2 - 4 } & Social work vacancies & $2013-17$ \\
\cline { 2 - 4 } & $\begin{array}{l}\text { Turnover of social } \\
\text { workers }\end{array}$ & CSCW & $2013-17$ \\
\cline { 2 - 4 } & Agency workers $^{4}$ & CSCW & $2013-17$ \\
\cline { 2 - 4 } & Caseloads $^{5}$ & CSCW & $2013-17$ \\
\hline
\end{tabular}

The demand indicators from Table 2 were converted to rates per 10,000 child population, confidence ratings for $\mathrm{CIN}$ censuses checked for each variable and records with the lowest rating reviewed for the extent of missing data and implausibly high or low entries that might undermine the analysis. For the trend analysis, key indicators for all LAs were plotted over time to identify continuities and changes. For the correlation analysis, Spearman's rank correlations were used to establish associations between key variables. The analysis was run separately for each year in order to check for stability in the period in question (2014-17). P-values were obtained for the correlations, effectively testing if they could have arisen by chance from an uncorrelated population. Results from the analysis of trends and correlations were compared with the previous five years (2009-14), a period seen as broadly comparable in terms of the consistency of reporting requirements. In doing so, there was an a-priori interest in checking the findings of Hood et al. (2016a), who had suggested that patterns of provision linked to levels of deprivation-related demand were connected also to indicators of expenditure and workforce stability.

\section{Findings}


Hood, R., Goldacre, A., Gorin, S. and Bywaters, P. (2019) Screen, ration and churn: demand management and the crisis in children's social care, British Journal of Social Work (in press)

Analysis of trends

Trends in demand indicators over the three-year period 2014-2017 were compared with the previous five years where data was available. The results are summarised below with respect to the key thresholds following referral.

Figure 1: Referrals, Children in Need (CIN) and Assessments

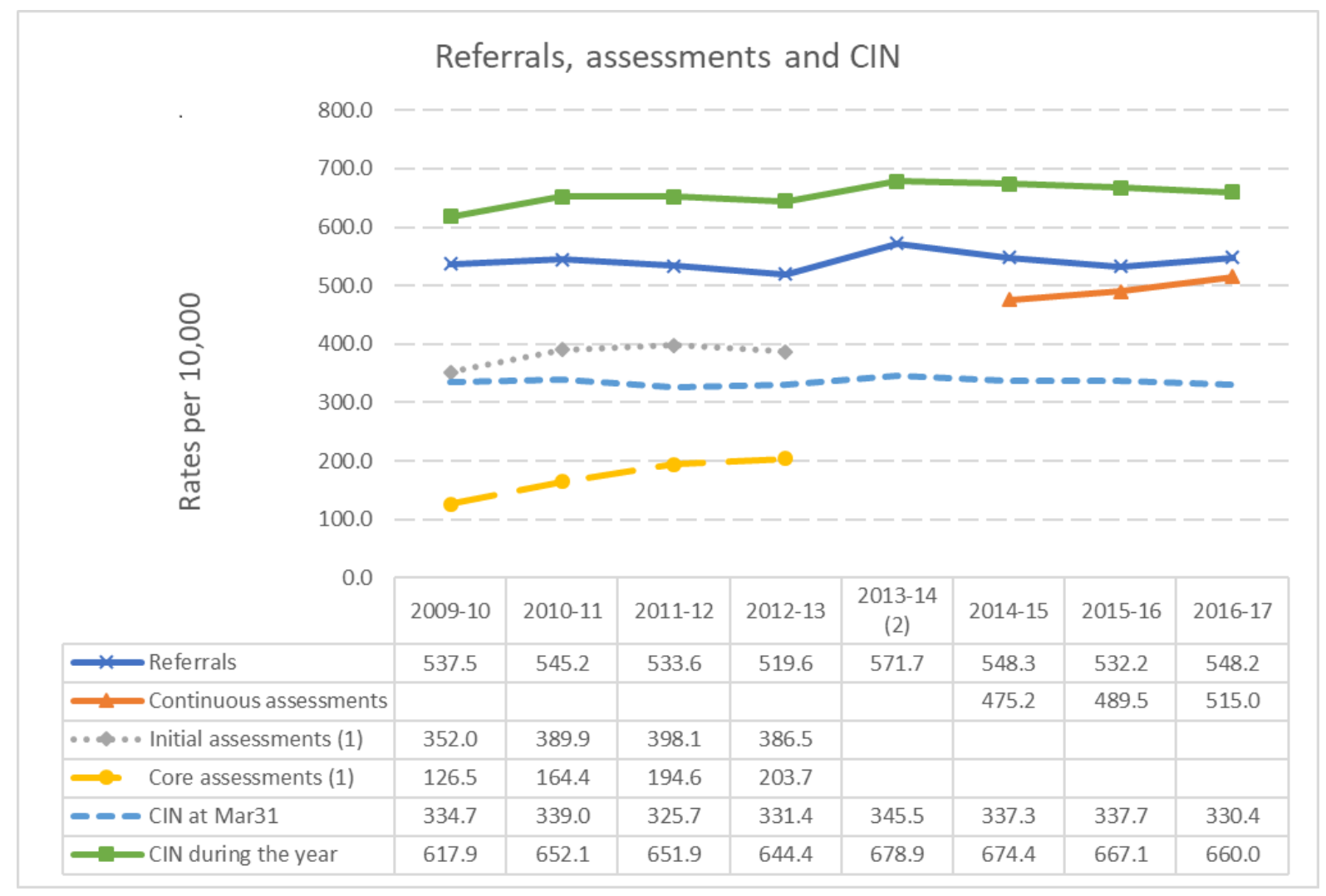

Notes

(1) Initial and core assessments were replaced during 2013-14 with continuous (child and family) assessments

(2) Figures for assessments in 2013-14 are not shown as this was a transition year between initial/core and continuous assessments.

Figure 1 shows that referral rates remained stable over the period 2014-17 and were only slightly higher in 2017 than in 2009. A similar picture emerges of children in need, annual rates of which barely changed over the eight year period shown here. Rates of 'continuous' child and family assessments, on the other hand, increased by $8 \%$ over the three years for which data were available. 
Hood, R., Goldacre, A., Gorin, S. and Bywaters, P. (2019) Screen, ration and churn: demand management and the crisis in children's social care, British Journal of Social Work (in press)

This trend has its counterpart in the screening that follows referral, which is illustrated in Figure 2. Rates of referrals leading to no further action decreased over the five year period for which data were available, although the figure in 2016-17 was slightly higher than in the previous year. In contrast, rates of children assessed as not meeting the threshold for CIN rose over the same period, particularly following the introduction of the continuous assessment.

Figure 2. Initial screening following referral

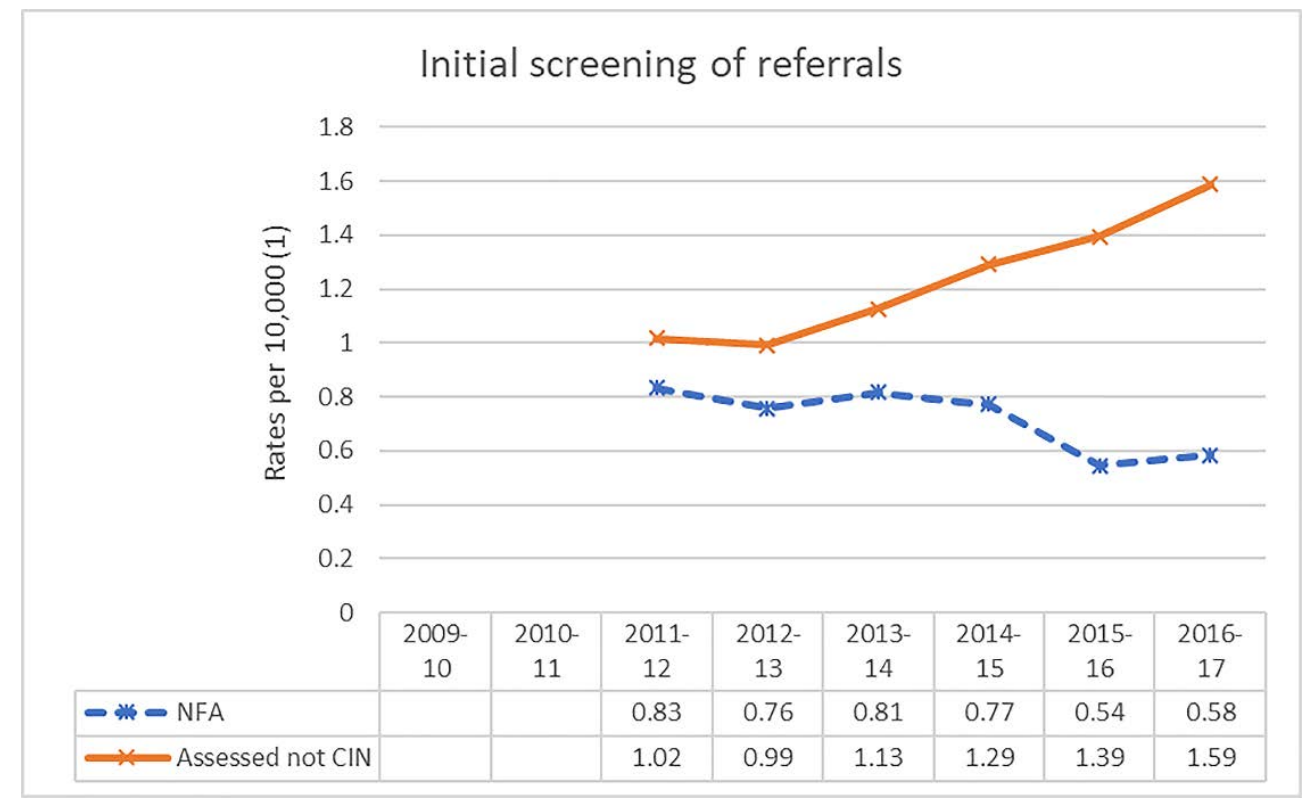

Trends for rates of CP interventions, which are illustrated in Figure 3, showed a steady rise in CP plans and CP conferences and a sharp rise in investigations. Rates of CP plans and conferences rose steadily from 2009-14 and then more gradually from 2014-17. Rates of Section 47 investigations in 2017 were more than double those in 2009. Overall, use of CP interventions has continued to outpace referrals and rates of CIN over the past three years.

Figure 3. $C P$ interventions 
Hood, R., Goldacre, A., Gorin, S. and Bywaters, P. (2019) Screen, ration and churn: demand management and the crisis in children's social care, British Journal of Social Work (in press)

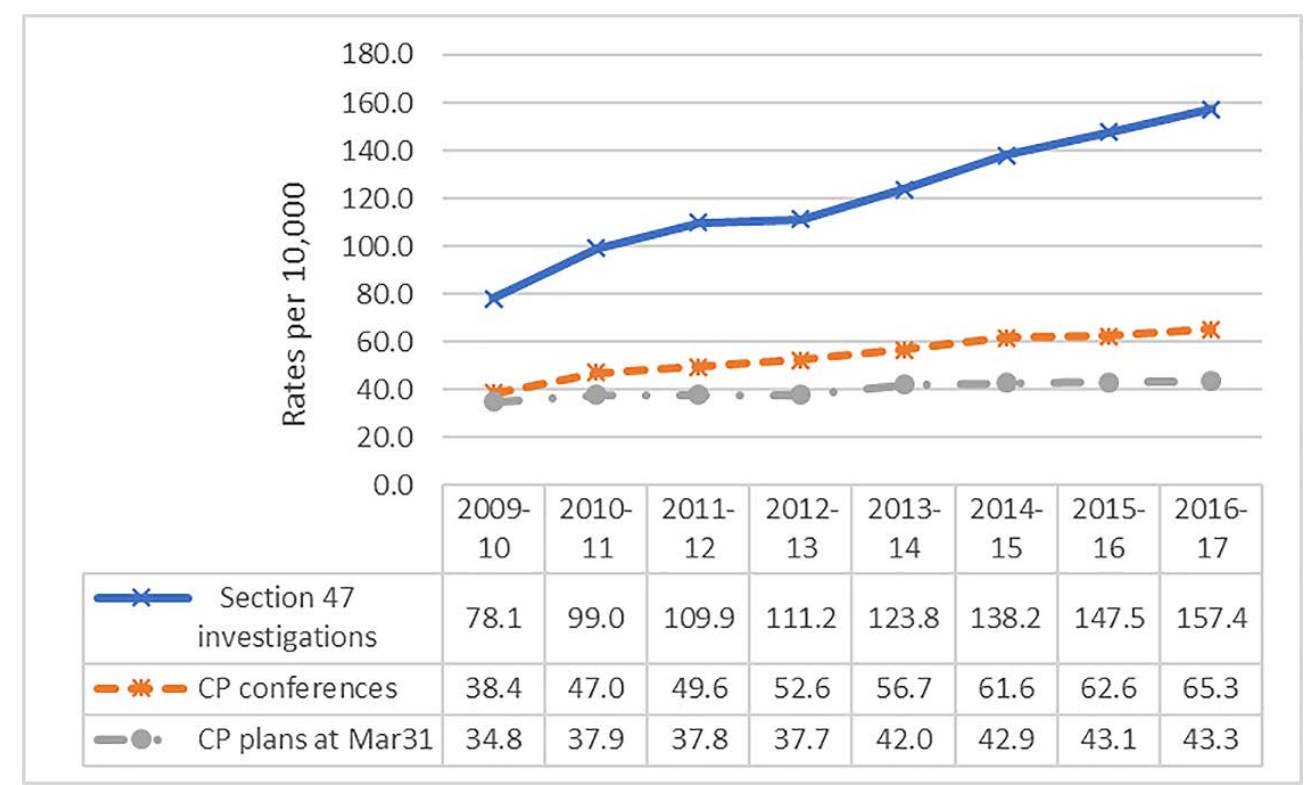

Statistics for Looked After Children (LAC) are illustrated in Figure 4. They show that rates of Care Orders and care proceedings rose steadily from 2014-17, and with one exception have increased every year since 2009. A contrasting trend was shown by accommodation under Section 20 (of the CA1989), which is a voluntary arrangement in which out-of-home care is subject to consent by the child's parents. This form of care declined from 2014-17, reversing a slight rise in the previous two years; rates of Section 20 accommodations in 2017 were $26 \%$ lower than in 2009.

Figure 4. Care proceedings and looked after children 
Hood, R., Goldacre, A., Gorin, S. and Bywaters, P. (2019) Screen, ration and churn: demand management and the crisis in children's social care, British Journal of Social Work (in press)

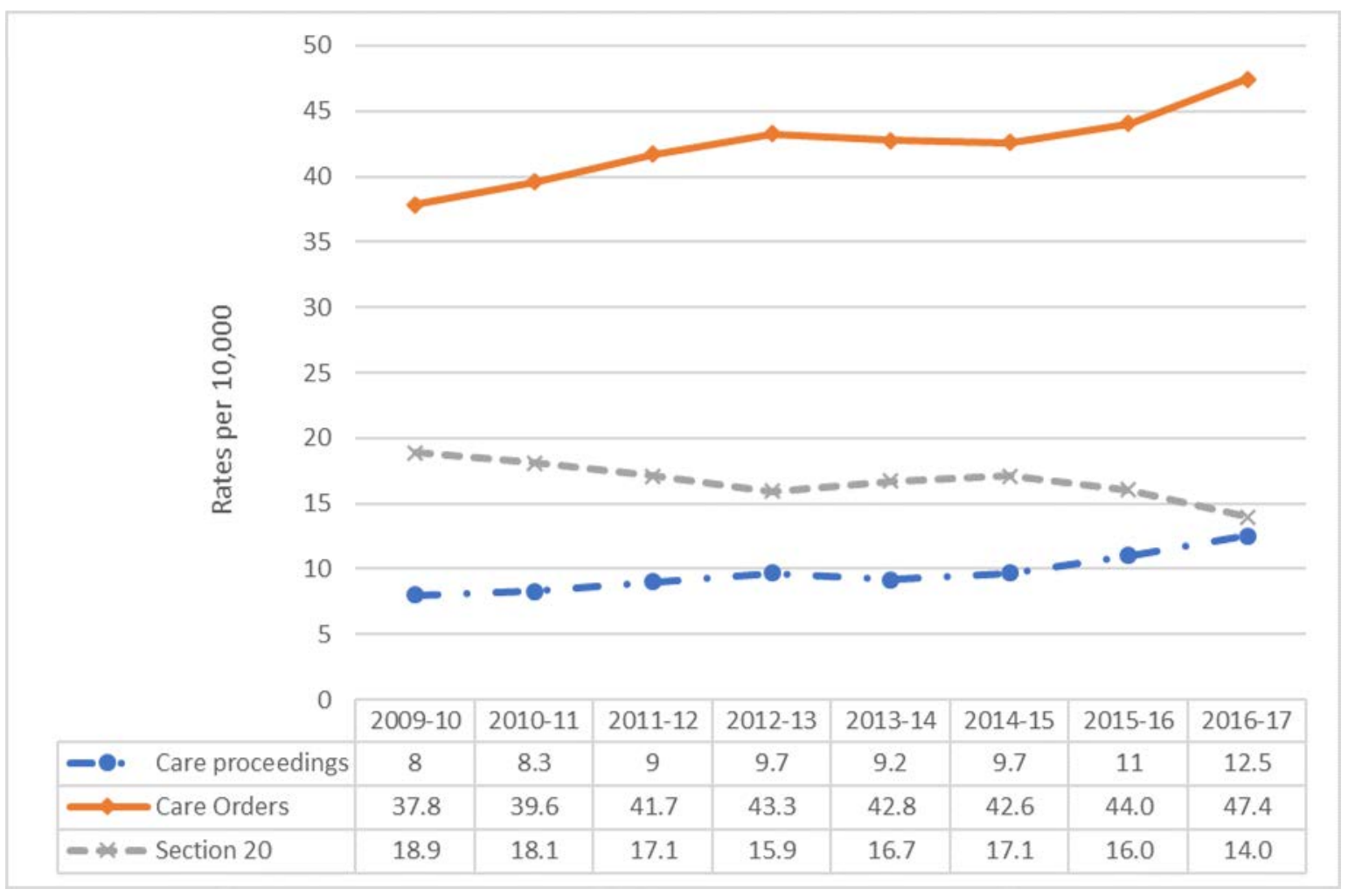

Another way of comparing these trends is to calculate the proportion of activity in one part of the system that is evident elsewhere following assessment, investigation or case conference. Figure 5 illustrates changes in the ratio between types of demand and provision at different thresholds. It shows a rise between 2014 and 2017 in the proportion of assessments, CP conferences, and Section 47 investigations relative to referrals. This has been a sustained trend since 2009. The proportion of care proceedings relative to CP plans fluctuated somewhat during 2009-13 but then rose steadily from 2014-17. Interestingly, the proportion of CP plans relative to referrals did not vary much from 2014-17, but remained at a higher level during this period than in the previous five years.

Meanwhile, the proportion of CP plans relative to CP conferences decreased every year from 201417, continuing a steady drop from the levels seen in 2009.

Figure 5. Ratios of demand and provision at different thresholds 
Hood, R., Goldacre, A., Gorin, S. and Bywaters, P. (2019) Screen, ration and churn: demand management and the crisis in children's social care, British Journal of Social Work (in press)

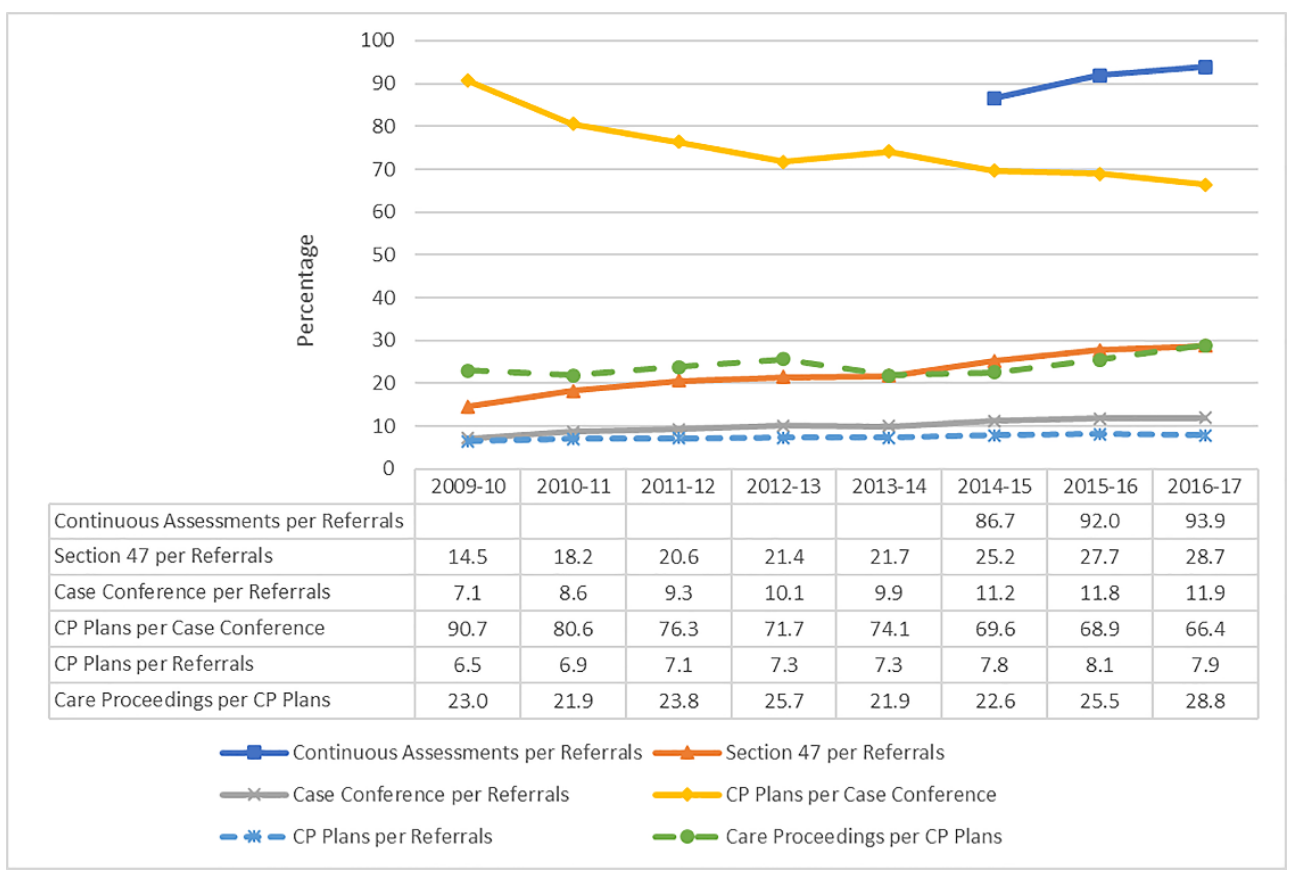

Analysis of correlations

Correlation analysis focused on the period 2014-17, and findings were subsequently compared with those reported by Hood et al. (2016a). The results reported below concern associations found to be significant $(p<0.05)$ across all three years $(2014-17)$, or in two out of three years where the same type of correlation (i.e. positive or negative) had been significant in all previous years. As expected, demand indicators across a range of thresholds correlated positively with each other and with LA deprivation levels. Patterns of service provision were also found to vary according to levels of deprivation-related demand. These variations are illustrated in Figure 6 below.

Figure 6. Variation in service provision linked to demand 
Hood, R., Goldacre, A., Gorin, S. and Bywaters, P. (2019) Screen, ration and churn: demand management and the crisis in children's social care, British Journal of Social Work (in press)

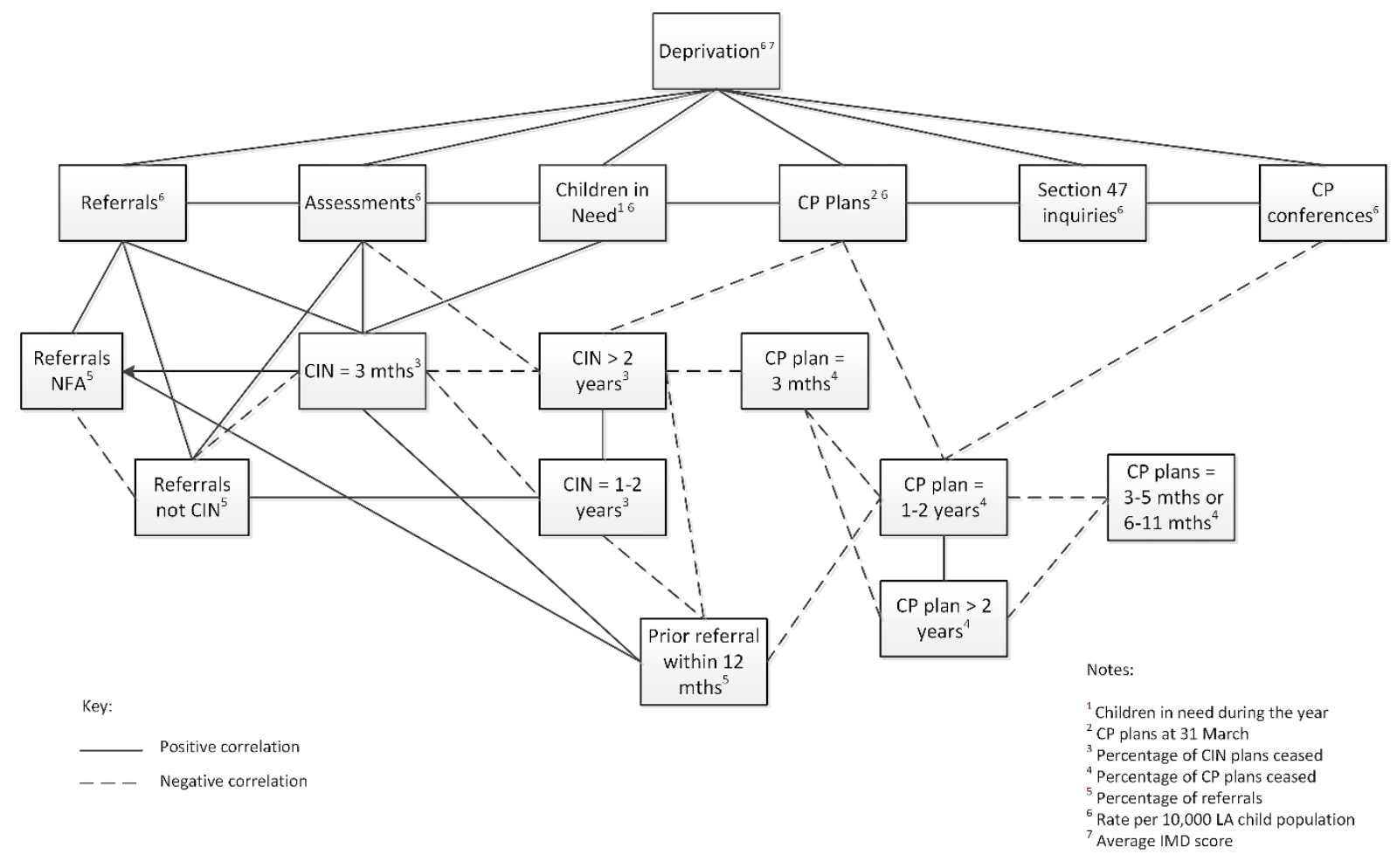

At the top of Figure 6, deprivation and demand indicators are linked together with solid lines, each of which represents a positive correlation identified every year from 2014-17. On the left, the correlations show that LAs experiencing higher rates of referrals tended to screen out more referrals as requiring no further action (NFA) and were also more likely to assess cases as not CIN. At the same time, LAs (LAs) who screened out more cases as NFA were less likely to screen out as not CIN indicated by the dotted line (negative correlation) between those two indicators. In the middle of the diagram, the correlations show that LAs with high levels of demand were more likely to close CIN cases earlier (<3mths), as illustrated by the positive correlations (solid lines) between $\mathrm{CIN}=3 \mathrm{mths}$ and demand indicators (referrals, assessments, CIN). High demand LAs were also less likely to work longer term with CIN (1-2yrs or $>2 y r s)$, as illustrated by the negative correlation (dotted line) between assessments and CIN $>2$ yrs. There were signs of a similar pattern with respect to CP plans, which are a subset of CIN. LAs with high rates of CP plans were less likely to have CP plans lasting 12yrs while LAs with higher rates of CP plans lasting 1-2yrs were less likely to have plans lasting 3$5 \mathrm{mths}$ or $6-11 \mathrm{mths}$. Finally, at the bottom of the diagram, it is shown that LAs who screened out more referrals and worked shorter-term with CIN cases were more likely to have higher rates of rereferrals within 12 months. This is illustrated by the positive correlation (solid line) between prior referrals and $\mathrm{CIN}=3 \mathrm{mths}$, and the negative correlation (dotted line) between prior referrals and $\mathrm{CIN}$ $>2 y r s$. 
Hood, R., Goldacre, A., Gorin, S. and Bywaters, P. (2019) Screen, ration and churn: demand management and the crisis in children's social care, British Journal of Social Work (in press)

Rates of demand and provision per LA child population were also correlated with service ratios in different parts of the system. The results are summarised in Figure 7, which shows three distinctive patterns. First, the rate of referrals was found to correlate negatively with all subsequent levels of provision as a proportion of referrals. This is illustrated by the cascade of dashed lines on the right hand side of Figure 7. They essentially show that the more referrals were received, the less work was done with them. Second, the rate of demand at a given threshold was found to correlate positively with the ratio of demand at that threshold as a proportion of demand at an earlier threshold. For example, higher rates of CIN were associated with a higher ratio of CIN per assessment. This is illustrated by the sequence of solid lines connecting rates in the middle to ratios on the left and right. The ratios on the left are based on 'neighbouring' thresholds, e.g. CP case conferences as a proportion of Section 47 investigations, while the ratios on the right all use referral rates as the denominator. The associations show that a higher ratio of activity at one threshold was linked to more work being carried out at the next threshold. The third pattern of correlations is illustrated by the sequence of diagonal dashed lines connecting rates in the middle with ratios based on neighbouring thresholds on the left. These were all negative correlations, which means that high rates of demand at one threshold (e.g. Section 47 investigations) were associated with a lower ratio of activity at the next threshold (e.g. CP conferences as a proportion of investigations). The second and third sets of correlations therefore operate in opposite directions, similarly to a negative feedback loop.

Figure 7. Variation in ratios of service provision linked to demand 
Hood, R., Goldacre, A., Gorin, S. and Bywaters, P. (2019) Screen, ration and churn: demand management and the crisis in children's social care, British Journal of Social Work (in press)

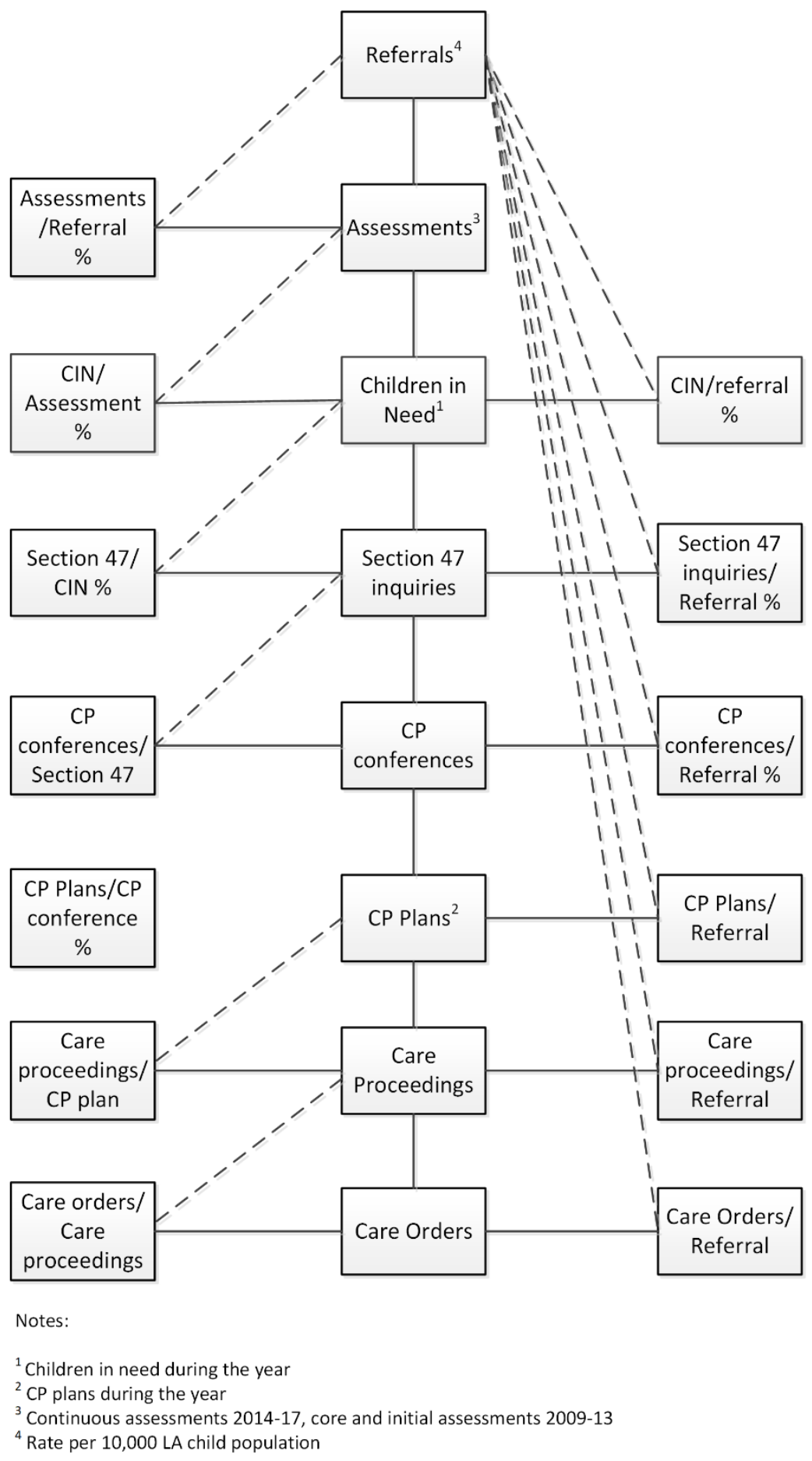

The correlations in Figures 6 and 7 provide evidence of a screening mechanism for managing demand. Overall, high rates of referrals and demand for CIN services were associated with a greater propensity to screen out children, particularly at the stages of referral and assessment, to close cases earlier and carry out less long term work. High levels of demand at a given point in the system were also associated with more screening in at that particular threshold - but were then followed by more screening out at the threshold that immediately followed. For example, LAs with high rates of Section 47 investigations tended to carry out more investigations per CIN but also to hold fewer case 
Hood, R., Goldacre, A., Gorin, S. and Bywaters, P. (2019) Screen, ration and churn: demand management and the crisis in children's social care, British Journal of Social Work (in press)

conferences per investigation. The only exception to this pattern was the ratio of $\mathrm{CP}$ plans to $\mathrm{CP}$ conferences and CP plans, where significant correlations (with CP plans and CP conferences respectively) were not consistently found every year. Overall, the findings therefore suggest that screening occurred not only in response to external demand (i.e. referrals received from outside the system) but also in response to internal demand (i.e. interventions escalated from inside the system). In turn, rates of re-referrals (within 12 months) were higher not only in LAs that screened out more referrals and closed cases earlier but also in LAs that were less inclined to escalate from CIN to $\mathrm{CP}$.

Variations in service provision linked to expenditure data were the next set of correlations to be analysed, as summarised below in Figure 8 . It shows that higher deprivation levels were linked to higher levels of total spending on services for children and with higher rates of spending on children's safety per LA child population. This was to be expected since these LAs had higher levels of deprivation-related demand, so that higher spending per LA child population was associated with higher rates of CP plans and care orders as well as referrals, assessments and CIN. However, a different pattern of correlations emerged when spending on children's safety was measured per child in need. Although there was a positive correlation between both types of expenditure, LAs with higher levels of demand (referrals, assessments, CIN, CP plans and care orders) were actually found to spend less on children's safety per child in need. In turn, LAs with higher levels of expenditure per CIN tended to have lower rates of CIN per social worker and lower caseloads (although this last indicator was only available for two years). LAs that spent more on children's safety per CIN were also less likely to close CIN cases early (at 3 months) and more likely to work longer term with CIN (12 years or over 2 years). Overall, these correlations are suggestive of a rationing mechanism of demand management, serving to reduce expenditure-per-child for those in need of a service.

Figure 8. Variation in service provision linked to expenditure 
Hood, R., Goldacre, A., Gorin, S. and Bywaters, P. (2019) Screen, ration and churn: demand management and the crisis in children's social care, British Journal of Social Work (in press)

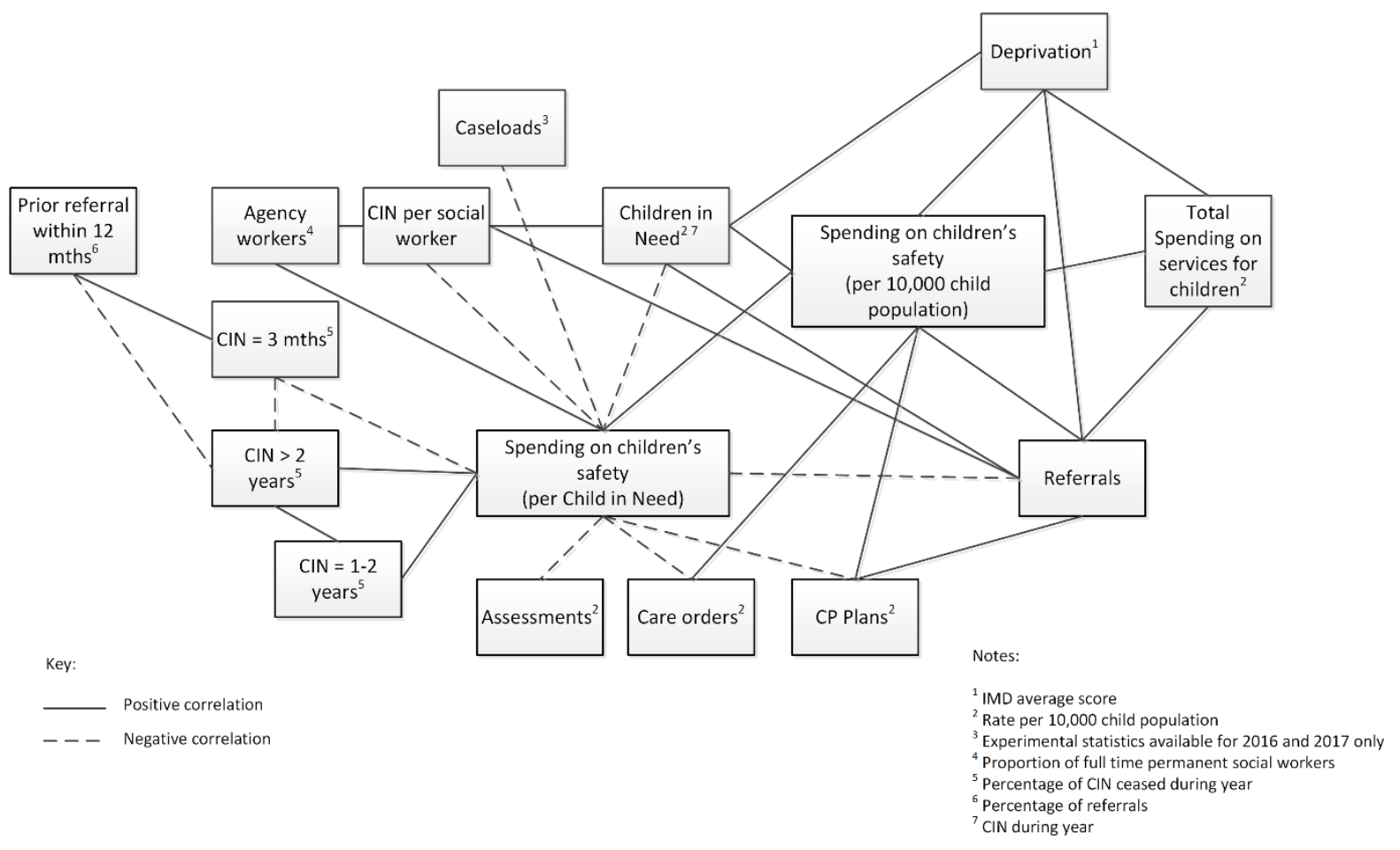

Variations in service provision linked to workforce indicators were the final set of correlations to be analysed. The results are summarised below in Figure 9, which shows links between the variations in demand (measured by rates of referrals and $\mathrm{CIN}$ ), expenditure (measured by spending on children's safety per child in need) and indicators of workforce stability: rates of agency workers, vacancies and turnover of social workers. The three workforce indicators all correlate positively with each other. Higher levels of demand are associated with higher rates of CIN per social worker and lower rates of spending per CIN. In turn, LAs with higher rates of CIN per social tend to have higher rates of agency workers, turnover and vacancies. Overall, these correlations suggest that the rationing response to high levels of demand is connected to a churn mechanism of demand management, where churn is understood as workforce instability caused by high rates of turnover, vacancies and agency staff.

Figure 9. Variations in service provision linked to workforce stability 
Hood, R., Goldacre, A., Gorin, S. and Bywaters, P. (2019) Screen, ration and churn: demand management and the crisis in children's social care, British Journal of Social Work (in press)

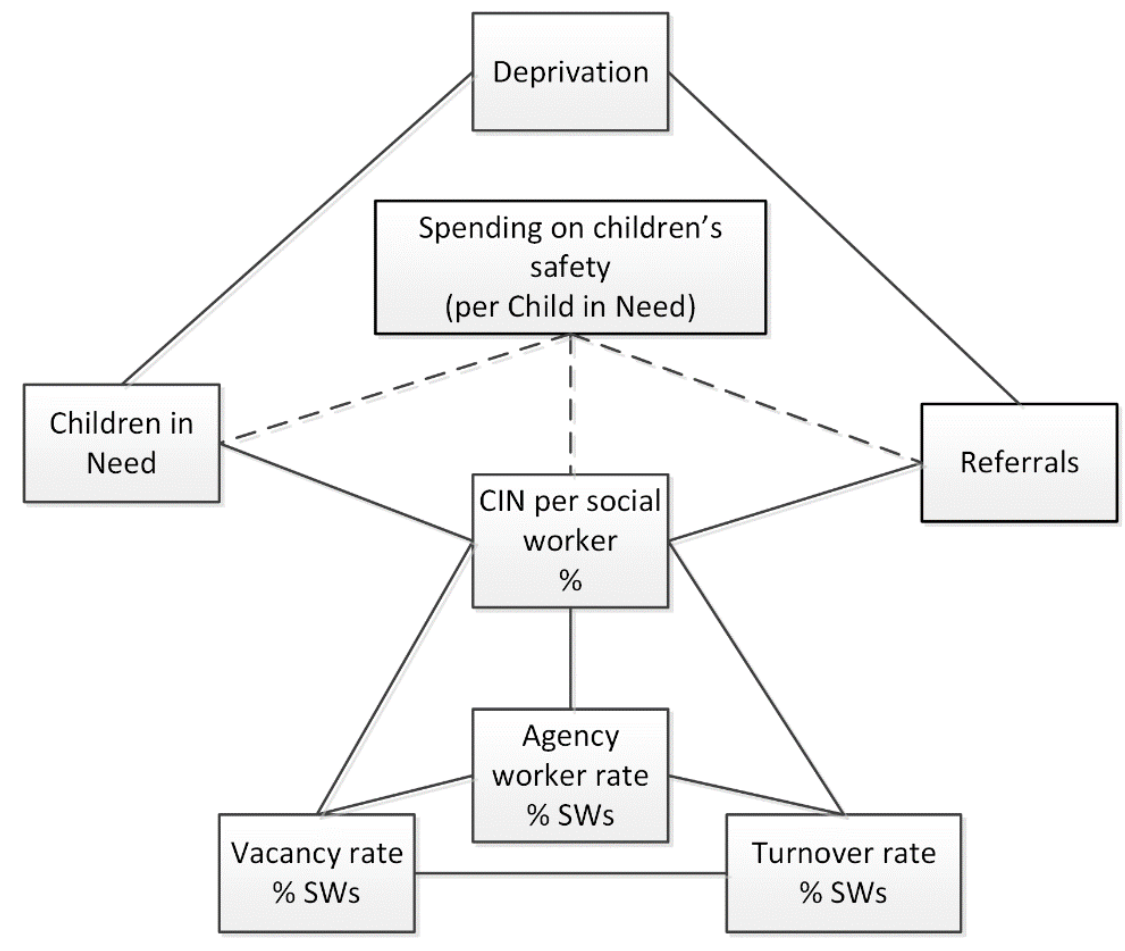

Summary of findings

- Rates of CP interventions, care proceedings and care orders rose every year from 2014-17, while rates of referrals and CIN remained largely unchanged. The same period saw implementation of the continuous child and family assessment, coinciding with an increase in assessment rates and a higher proportion of referrals receiving an assessment.

- National trends point to continued escalation in the use of CP interventions by LAs since 2009, particularly Section 47 inquiries and case conferences. Although overall rates of CP plans have risen, CP plans as a proportion of case conferences have fallen over this period.

- Rates of care proceedings increased while rates of accommodation under Section 20 decreased during 2014-17, both continuing trends observed since 2009 .

- Correlation analysis provided evidence for three interconnected mechanisms of demand management: screening, rationing and workforce churn.

- Screening refers to the tendency for LAs to either escalate (screen in) or filter (screen out) cases at different thresholds, in response to levels of demand. Overall, higher demand was associated with more screening out, particularly at referral and assessment, and shorter timeframes of work for children in need and children on CP plans.

- Higher demand at particular thresholds was associated both with more screening in at that threshold but with more screening out at the threshold that immediately followed. Such 
Hood, R., Goldacre, A., Gorin, S. and Bywaters, P. (2019) Screen, ration and churn: demand management and the crisis in children's social care, British Journal of Social Work (in press)

feedback loops allowed the system to respond not only to external but also internal variations in demand as cases progressed through the system.

- Rationing refers to the tendency for LAs with higher levels of demand to spend less on the children they work with. LAs with more referrals and CIN had lower levels of expenditure per CIN. These LAs also had higher rates of CIN per social worker, higher caseloads, were more likely to close cases early and less likely to work longer term with children.

- Workforce churn arose from the rationing response to high levels of demand, and refers to the tendency for LAs with higher rates of CIN per social worker to have higher rates of agency workers, turnover and vacancies.

\section{Discussion}

The findings reflect the complex relationship between demand (represented by the trends) and demand management (represented by the correlations). When it comes to demand, there is additional evidence of the 'investigative turn' noted by Bilson and Martin (2017). They found that the number of Section 47 inquiries that did not result in a CP plan was increasing faster than the number of inquiries, which tallies with the falling ratio of $\mathrm{CP}$ plans to conferences reported here. It suggests a greater willingness on the part of CSC services to investigate families, so that some children are being screened out at a later stage than would previously have been the case. Yet interpreting this as evidence of lower thresholds for statutory intervention may underplay the impact of changes to the non-statutory context. In particular, the scale of cuts to preventative services over recent years means that when universal services are worried about a child there will be limited options other than refer them to CSC, and also fewer protective factors when the risk to children is assessed. The resulting pressure is likely to 'push' cases into (and through) the statutory system, despite the LA's best efforts to maintain thresholds and manage demand.

One question, given the trajectory of these trends, is whether the legal distinction between a 'child in need' and a 'child at risk' is becoming blurred in the reality of practice. As Devine (2015) points out, unofficial conflation of these categories would impinge on families' freedom to consent to statutory assessment. The increase in rates of children assessed as 'not $\mathrm{CIN}^{\prime}$ ', when considered alongside static $\mathrm{CIN}$ and escalating CP rates, may point to an erosion in Section 17 provision, so that children who are unlikely to meet the threshold for Section 47 are more likely to be referred to nonstatutory provision or 'early help' as opposed to receiving support as CIN. If it were not for the high numbers of children being subjected to statutory assessments, or had non-statutory provision for 
Hood, R., Goldacre, A., Gorin, S. and Bywaters, P. (2019) Screen, ration and churn: demand management and the crisis in children's social care, British Journal of Social Work (in press)

children and young people not been cut so dramatically in recent years, this might even be seen as desirable. As it is, the data on re-referrals show that screening more children out earlier tends to result in more children entering the system at a later date.

The turn to CP over the past eight years could be viewed as part of a cyclical change in political ideology and economic necessity prompted by the financial crisis of 2008 , i.e. a gradual return to the protection-oriented system that prevailed in the UK and other Anglophone countries during the 1980s and early 1990s (Gilbert et al., 2011). In the intervening period (i.e. late 1990s to 2008), economic prosperity coincided with an increase in public spending by a centre-left government in the UK (voted out of office in 2010). During this period, CP was subsumed into a broader category of 'safeguarding', incorporating all services for children within a pyramidal model similar to public health (DfE, 2003). The shift to safeguarding created a broader mandate for government (and professional) involvement with families (Parton, 2011), and was associated with a surge in referrals to CSC (Devine and Parker, 2015). Yet the expansion of families' access to CSC was not initially accompanied by a corresponding increase in CP activity; indeed Devine (2017) argues that referral and assessment services were so overwhelmed with 'low level' referrals that they became less effective at identifying abuse. The findings here suggest that in more recent years agencies have been rebalancing towards $\mathrm{CP}$ but at the same level of referrals (and $\mathrm{CIN}$ ) built up in previous years when safeguarding was the dominant narrative and preventative services were well resourced. It is now becoming clear that such a policy is unsustainable for services, and ill-suited to help families already hard-hit by austerity measures (O'Hara, 2015).

The institutional and regulatory context of CSC has contributed to this crisis. Services have been shaped by a longstanding scandal-reform cycle, in which public outrage about deaths from child abuse is periodically channelled via media exposure and political posturing into a culture of toxic blame and risk-averse practice (Ayre, 2001; Jones, 2014). Attention should also be paid to the role of Ofsted, a non-ministerial government department that took over inspection of statutory CSC services in 2007. In its most recent three-year cycle of inspections, which coincided with the period examined above, Ofsted found the majority of LAs to be either inadequate or requiring improvement. During this time, anxiety about 'failing' an Ofsted inspection became pervasive (Jones, 2015) and recommendations focused heavily on procedural compliance (Hood et al., 2018). LAs that were rated inadequate also seemed to shift resources towards CP (Hood et al., 2016b). Ofsted's increasingly robust approach to inspections followed widespread criticism of positive ratings given to LAs shortly before scandals erupted about child sexual exploitation (Craven and Tooley, 2016) and 
Hood, R., Goldacre, A., Gorin, S. and Bywaters, P. (2019) Screen, ration and churn: demand management and the crisis in children's social care, British Journal of Social Work (in press)

deaths from child abuse (Elliott, 2009). It could be that the inspectorate itself has been affected by accountability pressures in the sector, reinforcing risk-averse tendencies in the sector and contributing to the shift towards late intervention.

There have been calls for sustainable approaches to managing demand (Thomas, 2018). However, the evidence presented here would suggest that demand management is part of the problem rather than the solution. Its main mechanisms are screening and rationing, which serve to control people's access to services as much as to address their problems (the latter would presumably be called 'meeting demand'). When LAs try to manage demand for statutory provision at the same time as implementing huge cuts for services 'lower down' the safeguarding pyramid, demand can be expected to go up, until it eventually overwhelms the higher tier services that were supposedly being gate-kept and rationed. In this study, demand management was also linked to workforce instability, which elsewhere has been found to increase the likelihood of a poor inspection outcome (Hood et al., 2016b). Similar counterproductive effects have been found in transactional services such as housing repairs or benefits payments, where efforts to manage demand by setting up backoffice functions to screen and process requests lead predictably to a deterioration in service quality (from end users' perspective) and agencies becoming overwhelmed with 'failure demand' (Seddon, 2008). Such systems tend to be designed around multiple handovers of work and rely on procedures, targets and audits to manage performance - all longstanding features of CSC (Munro, 2010).

LAs in areas of greater deprivation are under particular pressure, having borne the brunt of government cuts in the context of already high levels of demand (Bywaters et al., 2018). High deprivation LAs are also more likely to receive a poor inspection outcome than low deprivation LAs, particularly when unable to spend more than average (Webb and Bywaters, 2017). A combination of fiscal and social policy therefore seems to be forcing LAs into a vicious cycle of spiralling demand and counterproductive rationing, not helped by institutional anxiety about inspections. For beleaguered directors of children's services, Hobson's Choice beckons - do less demand management and deal with more demand now, or do more demand management and deal with more demand later on? Shifting resources from CP to preventative work and early help sounds like a sensible long term strategy but one difficult to implement in the context of unprecedented demand for $\mathrm{CP}$, acute financial constraints, and the political sensitivity of child abuse. It should also be remembered that when preventative programmes were generously funded during the early 2000 s, they were accompanied by an expansion of statutory involvement with children and families. 
Hood, R., Goldacre, A., Gorin, S. and Bywaters, P. (2019) Screen, ration and churn: demand management and the crisis in children's social care, British Journal of Social Work (in press)

In systems terms, demand management may be considered a single-loop solution to a crisis that requires a double-loop solution, i.e. a fundamental reappraisal of the assumptions underlying current approaches to CSC. Featherstone et al. (2014) argue that current orthodoxies include a transactional model of welfare based around bureaucratic processes, a child-focused orientation that overlooks the importance of families and networks, a preoccupation with risk linked to the pathologizing of groups and individuals, and an oppressive discourse of expertise. This paper has examined the empirical consequences of implementing such an approach in a sector that is now in crisis even on its own terms. The alternative paradigm outlined by Featherstone et al. (2014) would see child welfare agencies reconnect with the communities they serve, replacing 'screen and intervene' approaches with relational and developmental models of practice based on an ethics of care. However, while the sector has seen a great deal of innovation over recent years, the continuing crisis suggests that its problems are deep-rooted. It may be time to acknowledge that the 'safeguarding' paradigm heralded by Every Child Matters has finally run its course, a casualty of austerity politics and the bureaucratic, stigmatising system through which social investment was made. If progress is to be made, policymakers will need to disentangle the conflicting and contradictory demands that are pushing CSC services - and LAs - to the brink of collapse.

\section{Conclusion}

This paper has explored demand and demand management in children's social care, focusing on the last three years of national data returns and contextualising results from a historical perspective. The current crisis in demand, whose most visible symptom is the escalation in $\mathrm{CP}$ and care proceedings, emerged from an earlier period in which an expanded remit for CSC was predicated on generous government funding of universal and non-statutory services. In the current economic and political climate, the legacy of that period is proving catastrophic for agencies and families alike. It may also be time to question the legality of managing demand on the basis of thresholds intended as a framework of checks and balances for statutory intervention. Solving these issues will require political as well as institutional bravery. 
Hood, R., Goldacre, A., Gorin, S. and Bywaters, P. (2019) Screen, ration and churn: demand management and the crisis in children's social care, British Journal of Social Work (in press)

\section{References}

Action for Children, National Children's Bureau and The Children's Society (2017) Turning the Tide, available online: https://www.childrenssociety.org.uk/what-we-do/resources-andpublications/turning-the-tide, Last accessed 26 July 2018.

Association of Directors of Children's Services (ADCS) (2017) A country that works for all children, available online:

http://adcs.org.uk/assets/documentation/ADCS_A_country_that_works_for_all_children_FI NAL.pdf, Last accessed: 26 July 2018.

Ayre, P. (2001) 'Child protection and the media: Lessons from the last three decades', British Journal of Social Work, 31(6), pp. 887-901.

Bilson, A., Featherstone, B. and Martin, K. (2017) 'How child protection's "investigative turn" impacts on poor and deprived communities", Family Law Journal, 47(4), pp. 416-419.

Bilson, A. and Martin, K. (2016) 'Referrals and Child Protection in England: One in Five Children Referred to Children's Services and One in Nineteen Investigated before the Age of Five', British Journal of Social Work, p. bcw054.

Bilson, A. and Martin, K. (2017) 'Referrals and Child Protection in England: One in Five Children Referred to Children's Services and One in Nineteen Investigated before the Age of Five', The British Journal of Social Work, 47(3), pp. 793-811.

Broadhurst, K. and Mason, C. (2017) 'Birth parents and the collateral consequences of court-ordered child removal: Towards a comprehensive framework', International Journal of Law, Policy and the Family, 31(1), pp. 41-59.

Bywaters, P., Brady, G., Bunting, L., Daniel, B., Featherstone, B., Jones, C., Morris, K., Scourfield, J., Sparks, T. and Webb, C. (2018) 'Inequalities in English child protection practice under austerity: A universal challenge?', Child \& Family Social Work, 23(1), pp. 53-61.

Craven, B.M. and Tooley, J.N. (2016) 'Safeguarding Children: Ofsted and Regulatory Failure', Economic Affairs, 36(1), pp. 64-79.

Department for Education (DfE) (2017) Characteristics of children in need: 2016 to 2017 (England), available online: https://www.gov.uk/government/statistics/characteristics-of-children-inneed-2016-to-2017, Last accessed: 26 July 2018.

Department for Education and Skills (2003) 'Every Child Matters: Presented to Parliament by the Chief Secretary to the Treasury by Command of Her Majesty, September 2003', London, TSO.

Devine, L. (2015) 'Considering social work assessment of families', Journal of Social Welfare and Family Law, 37(1), pp. 70-83.

Devine, L. (2017) 'Rethinking child protection strategy: Progress and next steps', Seen and Heard, 26(4), pp. 30-49.

Devine, L. and Parker, S. (2015) 'Rethinking child protection strategy: Learning from trends', Bristol, Centre for Legal Research, University of the West of England.

Elliott, D. (2009) 'The Failure of Organizational Learning from Crisis - A Matter of Life and Death?', Journal of Contingencies and Crisis Management, 17(3), pp. 157-168.

Featherstone, B., White, S. and Morris, K. (2014) Re-imagining child protection: Towards humane social work with families, Bristol, Policy Press.

Gibbons, J., Conroy, S. and Bell, C. (1995) 'Operating the child protection system', London, HMSO.

Gilbert, N., Parton, N. and Skivenes, M. (2011) 'Changing patterns of Response and Emerging Orientations', in Gilbert, N., Parton, N. and Skivenes, M. (eds), Child Protection Systems: International Trends and Orientations, New York, Oxford University Press.

Hardiker, P., Exton, K. and Barker, M. (1991) Policies and Practices in Preventive Child Care, Aldershot, Ashgate.

Hood, R. (2015) 'A socio-technical critique of tiered services: implications for interprofessional care', Journal of Interprofessional Care, 29(1), pp. 8-12. 
Hood, R., Goldacre, A., Gorin, S. and Bywaters, P. (2019) Screen, ration and churn: demand management and the crisis in children's social care, British Journal of Social Work (in press)

Hood, R., Goldacre, A., Grant, R. and Jones, R. (2016a) 'Exploring Demand and Provision in English Child Protection Services', British Journal of Social Work, 46(4), pp. 923-941.

Hood, R., Grant, R., Jones, R. and Goldacre, A. (2016b) 'A study of performance indicators and Ofsted ratings in English child protection services', Children and Youth Services Review, 67, pp. 5056.

Hood, R., Nilsson, D. and Habibi, R. (2018) An analysis of Ofsted inspection reports for children's social care services in England, Child \& Family Social Work, Advance access published 2 September 2018, https://onlinelibrary.wiley.com/doi/abs/10.1111/cfs.12607.

Jones, R. (2014) The story of Baby P: Setting the record straight, Bristol, Policy Press.

Jones, R. (2015) Ofsted doesn't recognise the practice chaos and professional carnage it leaves in its wake, Community Care, published online: http://www.communitycare.co.uk/2015/05/07/ofsted-doesnt-recognise-practice-chaosprofessional-carnage-leaves-wake/,

Local Government Association (LGA) (2017) Children's social care at breaking point, council leaders warn, available online: https://www.local.gov.uk/about/news/childrens-social-carebreaking-point-council-leaders-warn, Last accessed: 26 July 2018.

Masson, J.M. and Dickens, J. (2013) 'Partnership by law? The pre-proceedings process for families on the edge of care proceedings', Bristol, School of Law, University of Bristol and the Centre for Research on Children and Families, University of East Anglia.

Munro, E. (2010) 'The Munro Review of Child Protection Part One: A Systems Analysis', London, Department for Education.

O'Hara, M. (2015) Austerity bites: A journey to the sharp end of cuts in the UK, Bristol, Policy Press.

Parton, N. (2011) 'Child Protection and Safeguarding in England: Changing and Competing Conceptions of Risk and their Implications for Social Work', British Journal of Social Work, 41(5), pp. 854-875.

Seddon, J. (2008) Systems Thinking in the Public Sector, Axminster, Triarchy Press.

Thoburn, J., Wilding, J. \& Watson, J. (2000) 'Family Support in Cases of Emotional Maltreatment and Neglect', London, The Stationery Office.

Thomas, C. (2018) Care Crisis Review: Factors contributing to national increases in numbers of looked after children and applications for care orders, available online:

https://www.frg.org.uk/involving-families/reforming-law-and-practice/care-crisis-review, Last accessed: 26 July 2018.

Webb, C. and Bywaters, P. (2017) There is clear evidence that links deprivation, expenditure and quality in children's services, Community Care, published online: https://www.communitycare.co.uk/2018/02/07/clear-evidence-links-deprivationexpenditure-quality-childrens-services/, last accessed 3 February 2019.

Webb, C.J.R. and Bywaters, P. (2018) 'Austerity, rationing and inequity: trends in children's and young peoples' services expenditure in England between 2010 and 2015', Local Government Studies, 44(3), pp. 391-415. 
Hood, R., Goldacre, A., Gorin, S. and Bywaters, P. (2019) Screen, ration and churn: demand management and the crisis in children's social care, British Journal of Social Work (in press)

\section{List of Figures}

Figure 1. Referrals, Children in Need (CIN) and Assessments

Figure 2. Initial screening following referral

Figure 3. Child protection interventions

Figure 4. Care proceedings and looked after children

Figure 5. Ratios of demand and provision at different thresholds

Figure 6. Variation in service provision linked to demand

Figure 7. Variation in ratios of service provision linked to demand

Figure 8. Variation in service provision linked to expenditure

Figure 9. Variations in service provision linked to workforce stability

\section{List of Tables}

Table 1. Thresholds following referral to CSC

Table 2. Indicators of demand and provision at different thresholds

Table 3. Other indicators 